\title{
Visceral mycoses in autopsied cases in Japan from 1989
}

to 2013:

increasing prevalence of mucormycetes.

\section{Introduction}

Many recent reports have described an increase of invasive mycosis in Japan (Kume et al. 2003; Kume et al 2011: Yamazaki et al 1999), including aspergillosis, mucormycosis, and so on.

Controlling infectious events, especially mycosis, are the key to improving the prognosis for certain types of patients such as leukemia, organ transplant recipients and so on.

Here, we show the updated report on autopsied cases with Visceral Mycoses (VM) from 1989 to 2013.

\section{Criteria of severe Infections}

\section{Defined as follows:}

-1) Direct cause of death

-2) Severe pulmonary infection involving both lobes of the lung n3) Severe visceral infections of $\mathbf{2}$ or more organ systems. mincluding those involving the central nervous systems.

-4) multi-organ systemic infection of 3 or more organ systems 15) Sepsis

\section{Annual frequency of visceral mycosis}

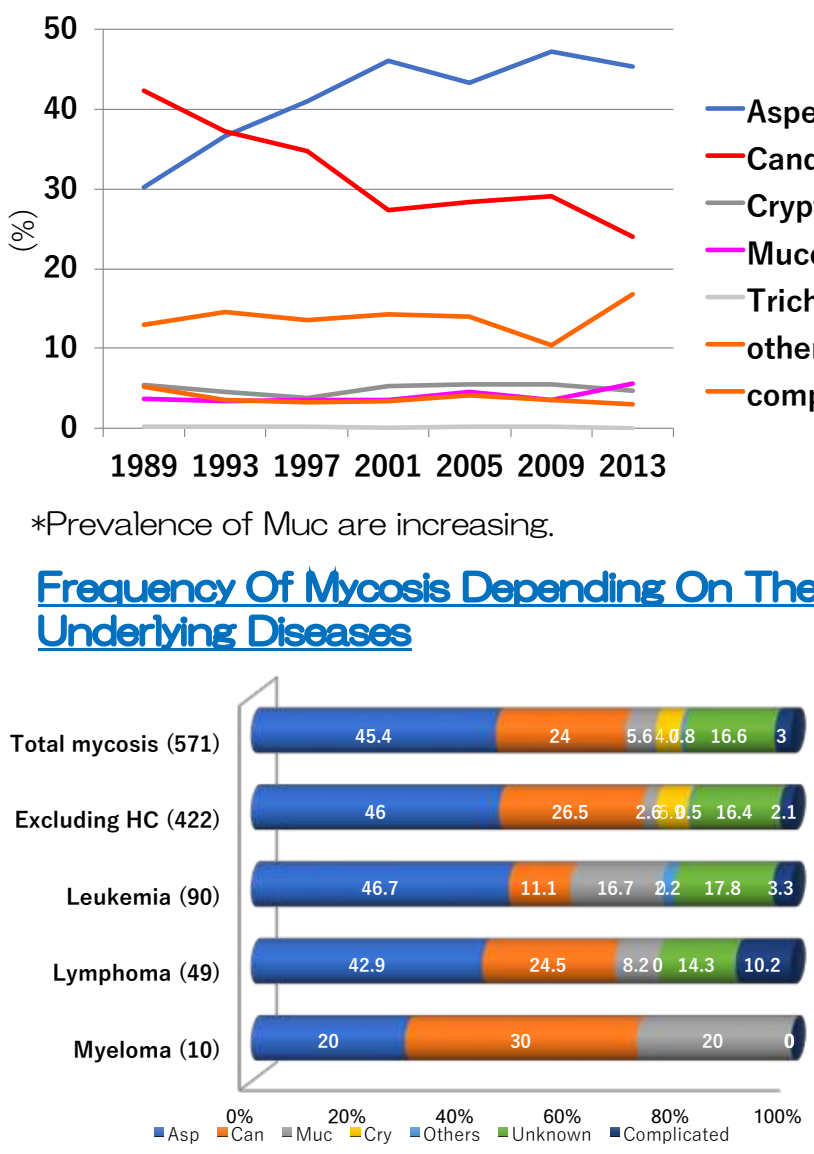

Asp:Aspergillus spp, Can: Candida spp, Muc: mucormycetes, Cry: Cryptococcus spp.

\section{Reference}

* Yamazaki T, and Kume H, JCM. 37; 1732-1738: 1999 * Kume H, et al. 53; 744-750:2003.

* Kume H, et al. Pathol Int. 47;15-24: 2006.

* Kume H, et al. Jpn J Med Mycol 52; 117-27.2011.

*Suzuki Y, Kume H et al. Med Mycol. 51;522-526: 2013.

*Suzuki Y, Kume H et al. Jpn J Med Mycol 2018 (revision).

\section{Material and Methods}

-Diagnostic Criteria: The description of each case is the responsibility of a reporting pathologist and depends on his or her ability to make a diasnostic determination.

- Definition Mycoses are defined as infectious caused by eumycotic organisms such as Candia, Aspersillous, Cryptococous, Mucormycetes, Trichosporon, and other fungal species.

-Actinomycetes and pnumocystis pneumonia were excluded.

-Superficial infections such as dermatophytoses were excluded.

\section{Data collection: Data on infectious events occurring from 2005 to 2012 were reported by the Japanese Society of Patholosy, in the Annual of Pathological Autopsy Cases in Japan".} -Those data were extracted and complicated to generate a
database for analysis using File Maker Pro Version 11 (FileMaker, Santa Clara, CA)

- The data on visceral mycoses reported in those databases were analyzed epidemiolosically every four years from 1989 to 2013 .

\section{- Underlying diseases of mycosis in 2013.}

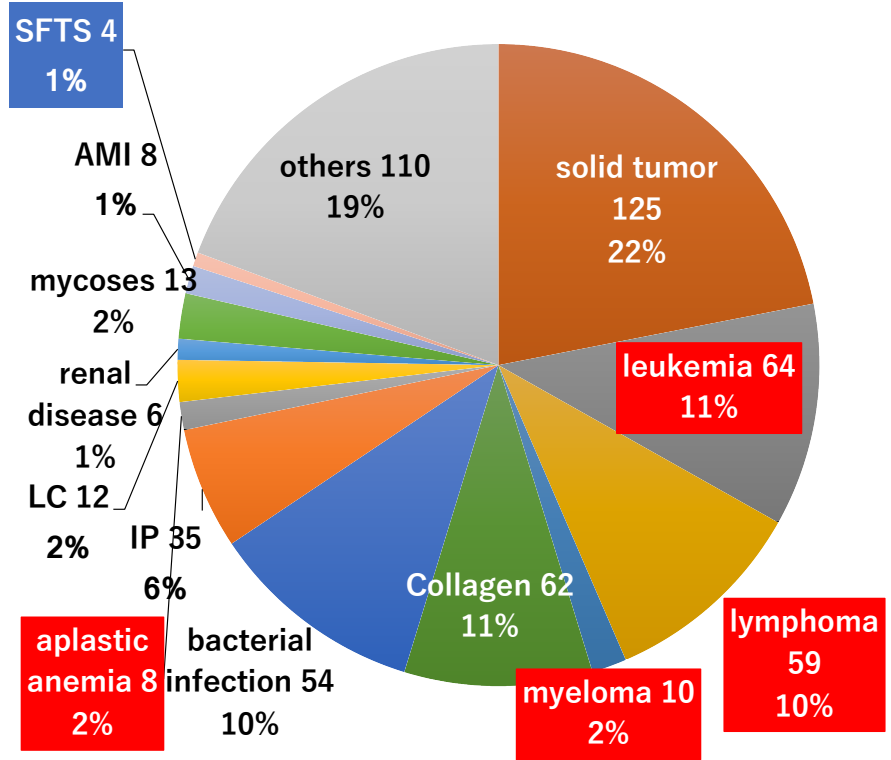

* Hematological cancers are main proportion.

\section{Results}

* A total of 11,149 cases were autopsied and 571 (5.1\%) cases of VM were observed in 2013.

* Noteworthy, cases with mucormycetes (Muc) were increasing, especially in leukemia. Muc cases also tended to show severe infection.

* Emerging diseases were also observed. Severe fatal thrombocytopenia syndrome (SFTS) cases showed high incidence of VM as a complication. * We reported cases with the rare mycoses due to Phialophra verrucosa, and Rhodotorula spp. in our analysis.

\section{Conclusion}

*The prevalence of VM remained steady, while an increase in cases with Muc should be focused.

*We should take note of breakthrough VM and emerging mycosis.

\section{ACKNOWLEDGEMENTS}

I would like to thank all the pathologists who provided the annual reports in Japan, and Dr. Aya Goto in the Department of Public Health 